\title{
Relation of number of positive lymph nodes to the prognosis of patients with primary gastric adenocarcinoma
}

\author{
C W Wu, M C Hsieh, S S Lo, S H Tsay, W Y Lui, F K P'eng
}

\begin{abstract}
Background-No nodal grouping category of gastric cancer has been universally accepted for the grading of the effectiveness of therapeutic regimens.

Aims-To establish an appropriate nodal grouping as a forecaster of distant disease and test its validity as a determinant in survival.

Patients-Five hundred and ten patients who underwent curative resections for gastric cancer were studied.
\end{abstract}

Methods-Retrospectively analyse the prognostic significance of the number of metastatic lymph nodes.

Results-A total of 17176 lymph nodes with an average of 34 per specimen were removed, of which $2811(16 \%)$ showed metastases. Among the 510 patients, 287 $(56 \%)$ had lymph node metastases, with an average of 9.8 per metastatic case. The survival of all patients was related to their nodal status, an abrupt decrease in survival was seen between 0 and 1 and 4 compared with 5 or more modes while little difference in survival existed among 1,2 , 3 , and 4 , and among $5,6,7$, and 8 positive nodes. Multivariate analysis showed that the number of positive nodes $(1-4,5-8$ versus $\geqslant 9$; relative risk $2 \cdot 2$ ) and depth of cancer invasion (three levels; relative risk 1.9) were independently correlated with survival. The current nodal stage was not a prognostic factor.

Conclusions-Gastric cancer patients with 0,1 to 4,5 to 8 , and $>9$ positive nodes may represent four appropriate prognostic groups and should be adopted for classification of nodal stage in gastric cancer.

(Gut 1996; 38: 525-527)

Keywords: positive nodes, gastric cancer, prognostic survival.

It is generally accepted that the two important factors influencing survival in resectable gastric cancer are the depth of invasion through the gastric wall and the presence or absence of regional lymph node involvement. ${ }^{12}$ To assess the extent of malignancy, determine prognosis, and aid in the selection of treatment, a TNM system $^{3}$ emphasising the two prognostic factors is commonly used. In this system, the assessment of lymphatic spread is based on its anatomical extension (level of nodal involvement). The same is true in the Japanese system, the General Rules for Gastric Cancer Study. ${ }^{4}$

During recent years a number of independent studies have shown that the prognosis in breast, ${ }^{5}$ colorectal, ${ }^{6}$ and gastric carcinoma ${ }^{7-11}$ was not only related to the presence or absence of lymph node involvement, but also the number of positive nodes. There is no universally accepted classification for gastric cancer. Similarly, no agreement has been reached for the presentation of findings, with regard to the natural history of gastric cancer patients, or the effectiveness of therapeutic regimens. We began to perform gastrectomy with radical lymph node dissection routinely for curable gastric cancer in 1987.12 13 The purpose of this paper is to present data that provide some insight into an appropriateness of nodal grouping category and its relation to survival.

\section{Methods}

A total of 510 patients with adenocarcinoma of the stomach treated in the Veterans General Hospital, Taipei, between December 1987 and May 1994, were entered into this study. Patients with two primary tumours or with gastric remnant cancer who had previously undergone distal gastrectomy for benign or malignant disease were excluded. All patients were regularly followed up. Deaths from causes other than gastric cancer were treated as censored findings at the time of death.

The relation between the current nodal stage classification and the number of metastatic lymph nodes was analysed. Nodal involvements are $n 1, n 2, n 3$, and $n 4$ according to the Japanese Rules. ${ }^{14}$ In the TNM classification, ${ }^{3} \mathrm{n} 1$ and $\mathrm{n} 2$ are defined as regional lymph nodes, whereas $\mathrm{n} 3$ and $\mathrm{n} 4$ as distant metastases. We chose age, sex, depth of cancer invasion, nodal stage, number of metastatic lymph nodes, site and size of tumour, and Lauren's histological classification ${ }^{15}$ as prognostic variables.

Data were stored on an IBM 4381 mainframe computer (IBM, Armonk, New York, USA) and statistical analyses carried out using a biomedical computer program (BMDP, Los Angles, California, USA). ${ }^{16}$ Cumulative survivals have been used to summarise the distribution of survival. The number of patients at risk four years after gastrectomy is shown to provide the reader with an idea of the reliability of the estimates at that point. In the univariate analysis the cumulative survival rate was calculated using the Kaplan-Meier approach and the equality of the survival 


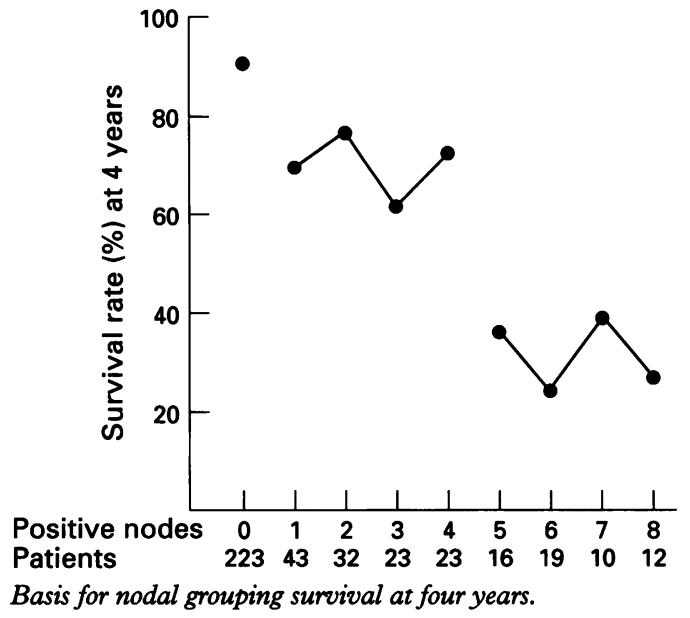

curves was tested using the method of generalised Wilcoxon analysis. In the multivariate analysis independent prognostic factors for survival were determined using a Cox proportional hazard model. Statistical significance was specified as $p<0 \cdot 05 .{ }^{17}$

\section{Results}

The mean age of the patients was 65 years (range 26 to 91) with a male: female ratio of 4.7:1. Most of them $(374 ; 73 \%)$ were advanced cancers. A total of 17176 lymph nodes with an average of 33.7 per specimen (range: 7-111) were removed, of which $2811(16.4 \%)$ showed metastases. Among the 510 patients, 287 $(56.3 \%)$ had lymph node metastases, with an average of 9.8 per metastatic specimen.

The four year survival rate was $91 \%$ for patients without nodal involvement compared with $39 \cdot 2 \%$ for patients with lymph node metastasis. When the survival of all patients was related to their nodal status, a distinct difference was seen between those with all negative nodes and those with one positive node (91\% versus $70 \%$ ). There was a little difference in survival between those having one, two, three, or four nodes, with tumour. A second sharp decrease in survival (from $73 \%$ to $35 \%$ ) was seen between patients with four positive nodes and those with five or more nodes containing tumour. While little difference in survival existed between those with five, six, seven, or eight, greater numbers of involved nodes were associated with a progressively worse prognosis (Figure and Table I).

TABLE I Number of positive nodes from gastric adenocarcinoma correlated with survival

\begin{tabular}{|c|c|c|c|c|c|}
\hline \multirow{2}{*}{$\begin{array}{l}\text { No of } \\
\text { nodes } \\
\text { positive }\end{array}$} & \multirow{2}{*}{$\begin{array}{l}\text { Initial } \\
\text { no of } \\
\text { patients }\end{array}$} & \multicolumn{4}{|l|}{ Survival (\%) } \\
\hline & & 1 Year & 2 Years & 3 Years & 4 Years \\
\hline $\begin{array}{l}0 \\
1-4 \\
1 \\
2 \\
3 \\
4 \\
\geqslant 5 \\
5-8 \\
5 \\
6 \\
7 \\
8 \\
\geqslant 9\end{array}$ & $\begin{array}{r}223 \\
121 \\
43 \\
32 \\
23 \\
23 \\
166 \\
57 \\
16 \\
19 \\
10 \\
12 \\
109\end{array}$ & $\begin{array}{l}98 \cdot 6(223) \\
91.0(121) \\
94.9(43) \\
89 \cdot 7(32) \\
86.4(23) \\
90.5(23) \\
62.7(166) \\
78.6(57) \\
75.0(16) \\
71 \cdot 1(19) \\
77 \cdot 8(10) \\
100.0(12) \\
54.8(109)\end{array}$ & $\begin{array}{l}94 \cdot 1(208) \\
79 \cdot 0(98) \\
83 \cdot 7(37) \\
81 \cdot 6(24) \\
61 \cdot 7(19) \\
85 \cdot 2(18) \\
32 \cdot 4(93) \\
54 \cdot 0(38) \\
45 \cdot 0(11) \\
40 \cdot 1(11) \\
77 \cdot 8(7) \\
66 \cdot 7(9) \\
21.9(35)\end{array}$ & $\begin{array}{l}90 \cdot 8(168) \\
74 \cdot 1(73) \\
80 \cdot 2(29) \\
77 \cdot 0(19) \\
61 \cdot 7(10) \\
72 \cdot 9(15) \\
22 \cdot 6(42) \\
37.6(23) \\
36 \cdot 0(6) \\
24 \cdot 0(5) \\
51.9(7) \\
53 \cdot 3(5) \\
15.5(19)\end{array}$ & $\begin{array}{l}90 \cdot 8(113) \\
70 \cdot 5(55) \\
70 \cdot 0(22) \\
77 \cdot 0(17) \\
61 \cdot 7(7) \\
72 \cdot 9(8) \\
16 \cdot 9(23) \\
26 \cdot 8(13) \\
36 \cdot 0(3) \\
24 \cdot 0(2) \\
38 \cdot 9(4) \\
26 \cdot 7(4) \\
12 \cdot 2(10)\end{array}$ \\
\hline
\end{tabular}

Figures in parentheses are number of patients at risk.
TABLE II Univariate analysis of clinicopathological factors in 287 patients with node positive gastric adenocarcinoma

\begin{tabular}{|c|c|c|c|}
\hline Variable & Patients & Survival & p Value \\
\hline \multicolumn{4}{|l|}{ Age } \\
\hline $\begin{array}{l}<65 \\
\geqslant 65\end{array}$ & $\begin{array}{l}119 \\
168\end{array}$ & $\begin{array}{l}35 \cdot 2 \\
42 \cdot 2\end{array}$ & 0.5674 \\
\hline \multicolumn{4}{|l|}{ Sex } \\
\hline Male & 237 & $37 \cdot 1$ & \\
\hline Female & 50 & $48 \cdot 5$ & $0 \cdot 1007$ \\
\hline \multicolumn{4}{|l|}{ Site } \\
\hline Upper stomach & 35 & $47 \cdot 3$ & \\
\hline Middle stomach & 64 & $45 \cdot 6$ & \\
\hline Lower stomach & 151 & $37 \cdot 8$ & \\
\hline Whole stomach & 37 & $29 \cdot 1$ & $0 \cdot 1599$ \\
\hline \multicolumn{4}{|l|}{ Size } \\
\hline $\begin{array}{l}<4 \mathrm{~cm} \\
4-8 \mathrm{~cm}\end{array}$ & $\begin{array}{r}40 \\
156\end{array}$ & $\begin{array}{l}61 \cdot 2 \\
39 \cdot 5\end{array}$ & \\
\hline$>8 \mathrm{~cm}$ & 91 & $27 \cdot 8$ & 0.0004 \\
\hline \multicolumn{4}{|l|}{ Lauren's histology } \\
\hline Intestinal type & $\begin{array}{l}117 \\
146\end{array}$ & $\begin{array}{l}47 \cdot 2 \\
31 \cdot 8\end{array}$ & \\
\hline $\begin{array}{l}\text { Diffuse type } \\
\text { Others }\end{array}$ & $\begin{array}{r}146 \\
24\end{array}$ & $\begin{array}{l}31 \cdot 8 \\
42 \cdot 5\end{array}$ & 0.0299 \\
\hline \multicolumn{4}{|l|}{ Positive nodes } \\
\hline $1-4$ & 121 & $70 \cdot 5$ & \\
\hline $\begin{aligned} & 5-8 \\
\geqslant & 9\end{aligned}$ & $\begin{array}{r}57 \\
109\end{array}$ & $\begin{array}{l}26 \cdot 7 \\
12 \cdot 1\end{array}$ & 0.0001 \\
\hline \multicolumn{4}{|l|}{ Nodal groups (Japanese rules)^ } \\
\hline n1 & 104 & $54 \cdot 4$ & \\
\hline n2 & 115 & $38 \cdot 8$ & \\
\hline n3 & 40 & $22 \cdot 2$ & \\
\hline n4 & 28 & $8 \cdot 8$ & 0.0001 \\
\hline \multicolumn{4}{|l|}{ Depth of cancer invasion } \\
\hline Mucosa and submucosa & 15 & 92.9 & \\
\hline Muscle and subserosa & 51 & $62 \cdot 4$ & \\
\hline Serosa & 221 & $29 \cdot 4$ & 0.0001 \\
\hline
\end{tabular}

${ }^{\star} \mathrm{n} 1$ and $\mathrm{n} 2$ are defined as regional lymph nodes, whereas $\mathrm{n} 3$ and $\mathrm{n} 4$ as distant metastasis in TNM system.

The cancer specific survival of patients was significantly influenced both by the number of positive nodes and their nodal group $(p=0.0001)$. In addition, survival was closely related to tumour size, Lauren's histological classification, and depth of invasion (Table II). The independent prognostic factors identified by multivariate analysis were number of positive nodes and depth of cancer invasion. The levels of positive nodes were no longer a prognostic factor (Table III).

\section{Discussion}

This study based on survival data provides nodal grouping categories that can be adopted for classification of nodal stage in gastric cancer. We found a small survival difference in patients with 1-4 and with 5-8 positive nodes. The survival rates in patients with $0,1-4,5-8$, and $\geqslant 9$ were $90.8 \%, 70.5 \%, 26.8 \%$, and $12 \cdot 2 \%$, respectively.

Most studies $^{7-11}$ on the prognostic role of the number of metastatic nodes in gastric cancer categorised positive nodes into 1-3 and $\geqslant 4$, which is customary in breast cancer. ${ }^{5}$ The findings in this study showed that four years after operation there was a considerable difference $(20 \%)$ in the survival between those with negative lymph nodes and those with 1-4 positive nodes. There was comparatively little difference in the outcome of patients with $1,2,3$, or 4 positive nodes, but there was a sharp decrease in survival when a fifth node was involved, emphasising the need to divide patients into the two positive nodal groups (Figure and Table I). Similar data can be seen in the report from Ichikura et al, ${ }^{11}$ although they categorised patients into those having 1-3 and $\geqslant 4$ positive nodes. In this study a $54 \%$ difference in the survival was found between 
TABLE III Multivariate analysis showing independent prognostic factors in patients with node positive gastric adenocarcinoma

\begin{tabular}{|c|c|c|c|c|}
\hline Variable (observed value) & Coefficient & $\begin{array}{l}\text { Standard } \\
\text { error }\end{array}$ & $\begin{array}{l}\text { Relative } \\
\text { risk }\end{array}$ & $\stackrel{p}{\text { Value }}$ \\
\hline \multirow{2}{*}{$\begin{array}{l}\text { Number of positive nodes }(1-4,5-9, \geqslant 9) \\
\text { Depth of cancer invasion (mucosa and } \\
\text { submucosa, muscle and subserosa, serosa) }\end{array}$} & 0.779 & $0 \cdot 108$ & $2 \cdot 180$ & 0.000 \\
\hline & 0.635 & $0 \cdot 241$ & $1 \cdot 887$ & 0.004 \\
\hline
\end{tabular}

those with 1 to 4 and those with $\geqslant 5$ positive nodes. Thus, it is more appropriate to classify patients as having 1 to 4 or $\geqslant 5$ positive nodes than to merely consider them as node negative or positive. The major difference in survival between those with 5 to 8 and those with $\geqslant 9$ positive nodes suggests that there is a risk in combining all patients with $\geqslant 5$ positive nodes into a single group. Such a unification may provide misleading information regarding the prognosis of patients and treatment strategy.

Of interest is the finding that a multivariate survival analysis including number of positive lymph nodes (categorised as $1-4,5-8$, and $\geqslant 9$ ) showed that number of positive nodes was the most important prognostic determinant (relative risk $2 \cdot 18$ ) and current nodal stage (either TNM system or Japanese Rules) was not independently prognostic (Tables II and III). Similar results were obtained recently by Adachi et $a l^{10}$ and Ichikura et al. ${ }^{11}$ These data show that the number of positive nodes rather than the level of nodal involvement (anatomical extension) should be adopted for classification of nodal stage in gastric cancer.

It is generally accepted that the depth of cancer invasion is also an important prognostic indicator in gastric adenocarcinoma. ${ }^{12}$ In this study, survival was significantly linked to the depth of cancer invasion, independently of the number of positive lymph nodes (Table III). The Lauren's histological classification is not an independent variable, which is in accord with those previously described by Haugstvedt et al ${ }^{18}$ and Rohde et al. ${ }^{19}$

This study was supported in part by a grant from National Science Council of the Republic of China (NSC 83-2331-B075-081).
1 Arveux P, Faivre J, Boutron MC, Piard F, Dusserre-Guion L, Monnet E, et al. Prognosis of gastric carcinoma after $L$, Mone $\mathrm{E}$, et al Propulation-based study using after curative surgery. A population-based study using multivariate crude and

2 Maruyama $\mathrm{K}$. The most important prognostic factors for gastric cancer patients. Scand $\mathcal{f}$ Gastroenterol 1987; 22 (suppl 133): 63-8

3 Hermanek P, Sobin LH. TNM Classification of malignan tumors. 4th ed, 2nd revision. Berlin: Springer-Verlag, 1992: 45-8.

4 Japanese Research Society for Gastric Cancer. fapanese classification of gastric carcinoma. Tokyo: Kanehara, 1995.

5 Fisher B, Bauer M, Wickerham L, Redmond CK, Fisher E. Relation of number of positive axillary nodes to the prognosis of patients with primary breast cancer. An NSABP update. Cancer 1983; 52: 1551-7.

6 Brodsky JT, Richard GK, Cohen AM, Minsky BD. Brodsky JT, Richard GK, Cohen AM, Minsky BD. Variables correlated with the risk of lymph
early rectal cancer. Cancer 1992; 69: 322-6.

7 Shiu MH, Perrotti M, Brennan MF. Adenocarcinoma of the stomach: a multivariate analysis of clinical, pathologic and treatment factors. Hepatogastroenterology 1989; 36 7-12.

8 Okusa T, Nakane Y, Boku T, Takada H, Yamamura M Hioki $\mathrm{K}$, et al. Quantitative analysis of nodal involvement with respect to survival rate after curative gastrectomy for carcinoma. Surg Gynecol Obstet 1990; 170: 488-94.

9 Makino M, Moriwaki S, Yonekawa M, Oota M, Kimura O, Kaibara N. Prognostic significance of the number of metastatic lymph nodes in patients with gastric cancer. $f$ metastatic lymph nodes in
Surg Oncol 1991; 47: 12-6.

10 Adachi Y, Kamakura T, Mori M, Baba H, Maehara Y, Sugimachi $K$. Prognostic significance of the number of positive lymph nodes in gastric carcinoma. $\mathrm{Br} \mathcal{F}$ Surg 1994; 81: 414-6.

11 Ichikura T, Tomimatsu S, Okusa Y, Uefuji K, Tamakuma $S$. Comparison of the prognostic significance between the number of metastatic lymph nodes and nodal stage based on their location in patients with gastric cancer. $f \mathrm{Clin}$ Oncol 1993; 11: 1894-900.

12 Wu CW, Hsieh MC, Tsay SH, Lui WY, P'eng FK Adenocarcinoma of midstomach. Clinical and pathoanatomic relation to lymph node metastases. $f$ Clin Gastroenterol 1994; 19: 259-63.

13 Wu CW, Hsieh MC, Lo SS, Tsay SH, Lui WY, P'eng FK Lymph node metastasis from carcinoma of the distal onethird of the stomach. Cancer 1994; 73: 2059-64.

14 Japanese Research Society for Gastric Cancer. The general rules for the gastric cancer study in surgery and pathology fpn $\mathcal{F}$ Surg 1981; 11: 127-45.

15 Lauren P. The two histological main types of gastric carcinoma. Diffuse and so-called intestinal type carcinoma: an attempt at a histoclinical classification. Acta Pathol Microbiol Scand 1965; 64: 31-49.

16 Dixon WJ. BMDP Statistical Software. Berkeley: University of California Press, 1988: 229-744.

17 Cox DR. Regression models and life tables. Fournal of the Royal Statistical Association 1972; 34: 187-220.

18 Haugstvedt TK, Viste A, Eide GE, Soreide O, members of the Norwegian Stomach Cancer Trial. Norwegian multicenter study of survival and prognostic factors in patients undergoing curative resection for gastric carcinoma. $\mathrm{Br} F$ undergoing curative resec
Surg 1993; 80: 475-8.

19 Rohde H, Gebbensleben B, Bauer P, Stutzer H, Zieschang $\mathrm{J}$. Has there been any improvement in the staging of gastric cancer? Findings from the German Gastric Cancer TNM Study Group. Cancer 1989; 64: 2465-81. 